\title{
Enhancing Decision Making Capabilities in Humanitarian Logistics by Integrating Serious Gaming and Computer Modelling
}

\author{
Za’aba Bin Abdul Rahim ${ }^{1, *}$, Giuseppe Timperio ${ }^{1}$, Robert de Souza ${ }^{1}$, Linda William² \\ ${ }^{1}$ The Logistics Institute Asia Pacific, National University of Singapore, 21 Heng Mui Keng Terrace \#04-01, Singapore 119613
}

${ }^{2}$ School of Informatics \& IT, Temasek Polytechnic, 21 Tampines Avenue 1, Singapore 529757

\author{
A R T I C L E I N F O \\ Article history: \\ Received: 30 January, 2020 \\ Accepted: 25 May, 2020 \\ Online: 11 June, 2020 \\ Keywords: \\ Supply Chain Management \\ Humanitarian Logistics \\ Serious Gaming \\ Computer Modelling \\ Enhanced Decision Making
}

\begin{abstract}
A B S T R A C T
The field of humanitarian logistics has in recent times gained an increasing attention from both academics and practitioners communities alike. Although various research groups have addressed theoretical and technical developments in humanitarian logistics using conventional research tools, applied research appears to be often dependent on practitioners' inputs. This paper is an attempt to fill the existing gaps between academic research and practitioners' needs and proposes an integrated framework that consists of serious games and computer modelling. The serious games component aims to raise awareness on humanitarian logistics issues as well as provide a platform to facilitate the acquisition of inputs from humanitarian practitioners. Based on these inputs, a computer model will be developed. To test the framework, a real-life case study about the prepositioning of strategic stockpiles in Indonesia, one of the countries with the highest disaster risk exposure on a global scale, was used. Findings of this work highlight the role of serious games as risk-free environments for players to design strategies enhancing disaster preparedness in conjunction with broadly used research methodologies such as computer modelling.
\end{abstract}

\section{Introduction}

This paper is an extension of work originally presented in 2018 Winter Simulation Conference (WSC), Gothenburg, Sweden by de Souza, et al. by [1]

ReliefWeb, a specialized digital service of the UN Office for the Coordination of Humanitarian Affairs (OCHA), reported that between the years 1994 and 2013, more than 6,500 natural calamities occurred globally. On average, 218 million lives were affected, and 1.35 million deaths were recorded annually [2]. In the year 2017 alone, for instance, more than 300 catastrophes occurred, of which more than half were natural [3]. These disasters claimed more than 11,000 people's lives, and it's estimated that they have caused an economic loss of over 300 billion US dollars. It is almost two times as many as the USD 180 billion economic losses estimated for the precedent year, and well above the average USD 190 billion monetary losses for the period 2005-2015 [3]. In addition, the combination of climate change, political and social crises, and progressive urbanization of

"Za'aba Bin Abdul Rahim, Email: zaaba@nus.edu.sg www.astesj.com

https://dx.doi.org/10.25046/aj050351 disaster-prone areas seem to push even further the frequency and scale of humanitarian crises globally.

Therefore, in a context of increased number and scale of humanitarian crises in conjunction with reduced resources, there is a need for greater efficiency in the deployment of relief assets. This is particularly relevant for logistics (purchasing, transportation, and storage), that is by far the biggest contributor to humanitarian expenditures (60-80\%) [4].

In humanitarian context, logistics can be defined as the activity of "planning, implementing and controlling the efficient, cost-effective flow of and storage of goods and materials as well as related information, from point of origin to point of consumption for the purpose of alleviating the suffering of vulnerable people" [5]. Compared to the commercial context, humanitarian logisticians are required to be cost-effective, agile, and time responsive.

Generally, disaster relief operations are run in a highly chaotic environment where the needs of affected population are in a fast and continuous development, and resources such as 
supplies, people, funds, and technologies are scarce [6] [7]. Hence, the logistics processes and disaster relief chains need to be streamlined to speed up the response time for the pressing need of critical supplies. Given these requirements, humanitarian supply chains require to be designed proactively, well ahead of the time when disasters occurr [8] [9].

To address supply chain issues, computer models are conventionally used. The main benefit of computer models is that they allow to replicate (to a certain extend) real-life operations in virtual environments. In turns, this allows to identify possible solutions, to test their feasibility in a virtual environment, and to mitigate the risk of making costly mistakes prior to the implementation in a real-world setting [10]. Amongst others, computer simulation appears to be the most popular decision support tool for supply chain design decisions as well as for the assessment of supply chain policies. A number of simulation techniques were used by other scholars to address research issues in the humanitarian logistics space including System Dynamics (SD) [11] [12], Discrete Event Simulation (DES) [13] [14] and Agent Based Simulation (ABS) [15] [16].

However, practical experience suggests that while the aforementioned research techniques are indeed relevant, practitioners' inputs are also a key component for research inquiries related with humanitarian logistics. In fact, while methodologies such as network optimization or simulation can be used to generalize and extend the humanitarian logistics preparedness through scenario-based analysis, it appears that to date there is no clear method facilitating the acquisition of inputs from practitioners.

In another front, there has also been an increase in the use of serious games to increase awareness and provide an avenue for wider audience to learn and experience humanitarian logistics, as well as to facilitate the acquisition of experiential inputs from practitioners. Serious games have been around for many years and have recently gained increased popularity [17]. Playing games increases interactivity among players and provide time-flexibility to pace their learning in their own time [18]. Serious games in humanitarian logistics provide a safe environment for the players to plan, implement and evaluate their humanitarian logistics strategies without the dangers of real-world consequences. It provides different sets of scenarios or environments compared to computer simulation models [19].

In this paper, we focus on developing a decision support framework integrating the use of serious games and computer models to address complex supply chain issues in the domain of disaster relief. We apply a role-playing simulation-based board game, titled THINKLog: Humanitarian Logistics Gameplay to gather inputs from practitioners. THINKLog is an interactive board game designed that can be scaled to include different scenarios for logistics and supply chain management including for humanitarian logistics. THINKLog is a learning framework where different scenarios can be generated by combining different concepts and challenges in logistics. One of the scenarios that is available is the Humanitarian Logistics Gameplay. This gameplay helps to introduce the importance and complexity of supply chain management and logistics in humanitarian context and deepen the understanding of humanitarian logistics for the players. The gameplay focuses on the warehouse location (Preparedness), inventory management and deliveries (Response).

This game has been played both locally (Singapore) and regionally (Southeast Asia). In this paper, the results from one of the game workshops are presented as an evidence that the game provided an interactive method to apply and experiment with supply chain concepts. The workshop was conducted with a official operating in disaster preparedness and response from multiple ASEAN countries at the ASEAN Coordinating Centre for Humanitarian Assistance on Disaster Management (AHA) Centre Executive (ACE) Programme in November 2018 in Jakarta, Indonesia.

Using the gathered inputs from the practitioners during and after the game session, a computer model is developed. As a case study, we applied it to a real-life case study about prepositioning of life-saving kits in Indonesia. Subsequently, a simulation model using AnyLogistix software was developed.

The rest of the manuscript is organized as follows. Section 2 debates the academic literature previously developed in this domain and focuses its attention on simulation-based serious games applied to supply chain and logistics and computer models in the niche of stockpile prepositioning. Section 3 describes the problem statement and methodology used in this paper. Section 4 describes the THINKLog - Humanitarian Logistics Gameplay game, a real-life simulation model and key findings of both. Section 5 summarizes the key findings of this work alongside its limitations and future extensions.

\section{Literature Review}

In this section, we review relevant academic literature in the areas of simulation-based serious games and computer simulation applied to the domain of humanitarian logistics and stockpile prepositioning.

\subsection{Simulation-Based Serious Gaming}

Recently, there has been an upward trend towards the use of serious games in creating awareness in specific areas and domains. They are widely used in areas like education [20], military [21], healthcare [22] and city planning [23]. Games help players grasp the learning objectives by providing hands-on engaging and motivating experiences. This manuscript will emphasize humanitarian simulation-based games.

Simulation-based games embed the process of hypothesizing, probing, and reflecting upon the simulated world within the game to promote learning and create awareness [24]. By using specific storylines in the game, players try to solve a particular task or challenge to learn specific concepts. Players are able to perform repeated experimentations and understand the consequences of their decisions, thus promoting players' incentive and learning transfer to the real-life context. [19]. Some other studies have even shown that these kind of games advanced players' awareness and understanding of scientific knowledge [19] [25].

There is a fair number of supply chain simulation-based games available in the market that are used as a learning tool to teach certain topics of supply chain management. In this paper, we looked into simulation-based games with humanitarian 
storylines. Two of such games are AFTERSHOCK [26] and STOP DISASTERS! [27]. AFTERSHOCK is a board game where players assumes roles of different agencies involved in the response of an emergency and its early phase of the recovery. STOP DISASTERS! is an online game whereby the player is needs to prepare for the impending disaster by improving the infrastructure in order to save the lives.

These games do offer a certain level of experiential experience or learning to the players. However, they do not provide an avenue to elicit current issues, especially faced by humanitarian logistics domain experts, practitioners and decision makers. There may be valuable information/data that may be captured, analyse and derived from the games that are not necessarily captured.

Table 1 shows the summary and comparison of the two aforementioned games against our proposed one namely THINKLog.

\subsection{Computer Modelling in Humanitarian Logistics}

Logistics system design with focus on storage and transportation systems have received significant attention in the domain of commercial supply chains [28], [29]. Nevertheless, the importance of humanitarian logistics applications has been recognized only in recent times. One of the areas receiving the greatest attention in the space of humanitarian logistics is stockpile prepositioning and network design.

Balcik \& Beamon (2008) are considered pioneers in this field. Their study analyses the facility location problem in consideration of constraints such as budget and capacity of facilities. The overarching goal of their work is to optimize the flow of relief supplies all the way to disaster affected zones. McCoy \& Brandeau [30] looked at storage and shipping policies and the main outcomes of their work include effective distribution strategies and trade-off between stock size and service level. Roh, et al. [31] analyzed the supply prepositioning location problem from both macro and micro perspectives using inputs from highlevel decision-makers and operational experts.

Simulation literature studies humanitarian logistics problems using different methods including system dynamics, discreteevent simulation, and agent-based modeling.

System dynamics (SD) is a modelling technique often used to evaluate the nonlinear behavior of complex systems, Basic elements of SD modelling are known as stocks, flows, internal feedback loops, table functions and time delays [32]. One of the first applications of SD in the humanitarian logistics space was by Besiou et al. [11]. Their work applies SD to the issue of fleet management. Costa et al. [12] instead used SD with the aim of addressing the challenge of coordination in disaster response.

Discrete-event simulation (DES) is a modelling technique used to sequence discrete events over time. Once a particular event occurs, the state of the system will change. No changes will occur between two consecutive events [33]. Iakovou, et al. [13] developed a DES model to assess the impact of emergency sourcing on supply chain performances. Noreña, et al. [14] used DES to understand the robustness of the logistics of medical supply in Bogotá (Colombia).
Table 1. Games Comparison

\begin{tabular}{|c|c|c|c|}
\hline & $\begin{array}{l}\text { STOP } \\
\text { DISASTERS! }\end{array}$ & AFTERSHOCK & $\begin{array}{l}\text { THINKLog } \\
\text { (humanitarian } \\
\text { logistics version) }\end{array}$ \\
\hline Topic & $\begin{array}{l}\text { Pre-disaster } \\
\text { buildings } \\
\text { capabilities and } \\
\text { defences }\end{array}$ & $\begin{array}{l}\text { Interagency } \\
\text { cooperation in } \\
\text { response to } \\
\text { emergency and early } \\
\text { recovery phase of a } \\
\text { humanitarian crisis }\end{array}$ & $\begin{array}{l}\text { Logistics and } \\
\text { facility location } \\
\text { identification in } \\
\text { humanitarian } \\
\text { context }\end{array}$ \\
\hline $\begin{array}{l}\text { Type of } \\
\text { game }\end{array}$ & Simulation & Simulation & Simulation \\
\hline Objective & $\begin{array}{l}\text { To build the } \\
\text { defence of an } \\
\text { existing structures } \\
\text { for the population } \\
\text { in face of an } \\
\text { upcoming disaster }\end{array}$ & $\begin{array}{l}\text { To address the } \\
\text { urgent humanitarian } \\
\text { needs of the local } \\
\text { population. }\end{array}$ & $\begin{array}{l}\text { To build a } \\
\text { warehouse based } \\
\text { in the concept of } \\
\text { Multi Criteria } \\
\text { Decision Making } \\
\text { (MCDM) to } \\
\text { deliver an } \\
\text { uninterrupted and } \\
\text { continuous supply } \\
\text { of the required } \\
\text { life-saving kits to } \\
\text { the disaster area }\end{array}$ \\
\hline $\begin{array}{l}\text { Type of } \\
\text { tasks }\end{array}$ & $\begin{array}{l}\text { Operation } \\
\text { activities/tasks }\end{array}$ & $\begin{array}{l}\text { Operation } \\
\text { activities/tasks }\end{array}$ & $\begin{array}{l}\text { Strategic planning } \\
\text { (in preparation } \\
\text { stage) and } \\
\text { operation } \\
\text { activities/tasks (in } \\
\text { response stage) }\end{array}$ \\
\hline $\begin{array}{l}\text { Playing } \\
\text { mode }\end{array}$ & Computerized & Board game & $\begin{array}{l}\text { Board game with } \\
\text { digital companion } \\
\text { app }\end{array}$ \\
\hline
\end{tabular}

Agent-based modeling (ABM) refers to a series of computer simulation techniques whereby the actions of autonomous predefined agents are simulated [15]. Horner \& Widener [16] used an integrated approach $\mathrm{ABM}$ and GIS to foresee the damage caused by heavy storms on the transportation network in use case of Florida City.

\subsection{Research Gaps}

Despite the significant body of literature available in the domain of stockpile prepositioning, to our knowledge it appears that most research groups have tackled humanitarian logistics issues, and facility location problems in particular, from a purely conceptual standpoint with limited understanding of practitioners' viewpoints. Although these approaches provide fine solutions to this class of problems, it is also evident that there is a need for supplementing them with practitioner perspectives. It is intended that, decision-makers will be able to gain insights on the following matter: 


\section{Z.B. Abdul-Rahim et al. / Advances in Science, Technology and Engineering Systems Journal Vol. 5, No. 3, 402-410 (2020)}

- How to leverage on serious games to acquire inputs from decision makers and practitioners?

- How to integrate serious-games and computer models to assure the robustness of the computer model and its relevance to the practice?

\subsection{The Contribution of The Current Research}

This paper demonstrates the applicability of the proposed framework for network design in the use case of Indonesia. The work presented in this manuscript will apply THINKLog and simulation to demonstrate the relevance of the proposed solution approach. The contribution of our study is on the integration of serious games and computer modelling with the aim of generating insights into the domain of network design using practitioner's inputs.

\section{Problem Statement and Methodology}

Indonesia is the 14th largest nation by size, spans across three time zones and counts over 260 million people living across more than seventeen thousand islands [9]. The country sits on the edges of four tectonic plates and is part of the so called "Ring of Fire". According to Statista [34], between 1900 and 2016, 113 earthquakes were recorded in the Indonesian archipelago, which claimed nearly 200,000 human lives. According to the Centre for Research and Epidemiology of Disasters, Indonesia ranks in the 'top 5 countries most frequently hit by natural disasters' after China, India, the Philippines, and the United States [35]

\subsection{Problem Statement}

When disasters hit in remote areas of the archipelago, existing response capacities are significantly stretched. Despite the efforts of the national authorities to boost inter-island and intra-island connectivity through infrastructure development [36], the existence of ad-hoc logistics hubs to store those critical inventories to be deployed in times of emergency, would be highly beneficial for the effective provision of humanitarian assistance. Hence, the case study will focus on the pre-positioning of relief supplies at strategic locations across Indonesia to improve country's logistics capabilities to respond to natural disasters.

\subsection{Methodology}

Because the problem statement requires the embedding of inputs from practitioners, decision makers, and humanitarian logistics domain experts, the integration of serious games for the collection of inputs, and computer simulation as an analytical closed form of analysis is proposed.

In particular, to address the identified problem statement, the following multi-phase framework encompassing two main steps was conceptualized and tested:

(1) Phase 1. Socializing the problem at hand with practitioners, decision makers, and humanitarian logistics domain experts, and gathering of inputs using serious games.

(2) Phase 2. Building the computer model and running scenario-based analysis for the identification of the solution to the problem at hand.
Figure 1 is an outline of the proposed framework which was tested in the use case of stockpile prepositioning in the use case of Indonesia using THINKLog game in integration and computer simulation in AnyLogistix.

\section{THINKLOG Game}

\subsection{THINKLOG Game, An Overview}

ThinkLog is an expandable interactive logistics and supply chain management board game that was designed specifically to help players in learning about SCM concepts. The game aims to complement teaching and learning activities in classrooms and workshops by introducing SCM concepts through roleplaying and simulation. The initial design of the game was for a pure board game play: main board, demand cards, gameplay/rules and game master [37]. This game also includes a digital companion application [38]. With the inclusion of this app, more SCM concepts and different scenarios of game play can be added, such as the Humanitarian Logistics game play.
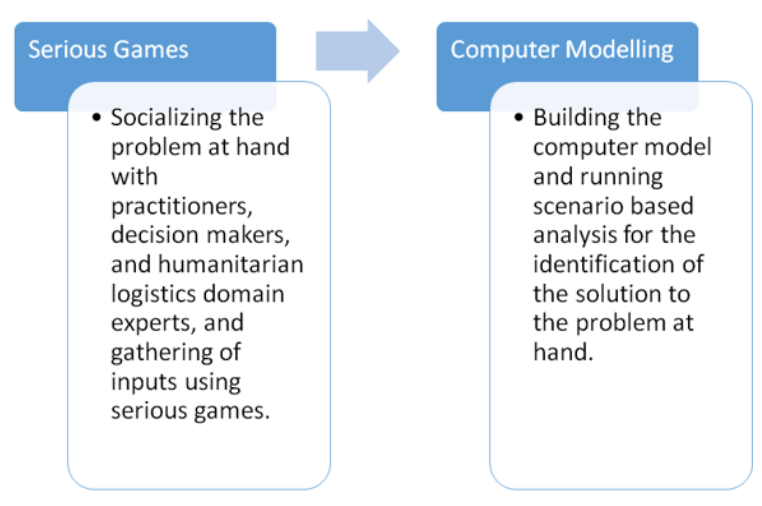

Figure 1. Proposed Framework

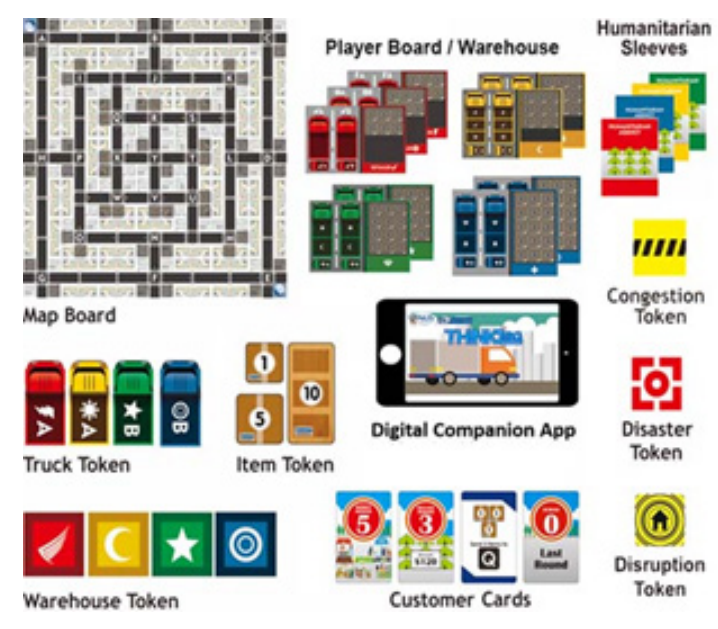

Figure 2: THINK:Log game components

\subsection{Humanitarian Logistics Gameplay}

The main learning objectives for this gameplay are to introduce the notions of Multi Criteria Decision Making (MCDM), and particularly its applications in warehouse location selection problems for disaster preparedness, while providing a high level 
view on the challenges related with information flow and coordination in logistics and supply chain management.

MCDM, that is a structured framework able to analyze decisions problems involving complex objectives concepts, is adapted in this gameplay to help the identification of possible locations for the warehouses [9], [39], [40].

There are two stages in this gameplay - Preparation and Response. In the Preparation, the players input their weightage to the criteria defined in the MCDM framework directly through the companion app. Figure 3 shows the input screen for the players. There are 5 criteria for consideration, including Distance, Congestion, Cost, Coverage and Risk. Figure 4 shows one of the criteria and its definition. The companion app will then generate recommended locations based on the weightage as input by the player. In the second stage namely Response, players will have to deliver the requested relief items to the affected population while taking into consideration the possible random events that may occur and disrupt their distribution operations. Examples of events include congestions and /or further calamities that may impede their logistics plan. Figure 5 shows the basic game flow of this game play.

Players assume the role of a Humanitarian Agency Officer in charge of designing and coordinating an uninterrupted and continuous flow of relief items to disaster affected areas. The player has to strategize the most optimal way to deliver such relief items. In the event where the player fails to deliver the required number of items within the stipulated time, the player will 'earn' a failure token as a penalty. The player with the least number of failure tokens wins the game.
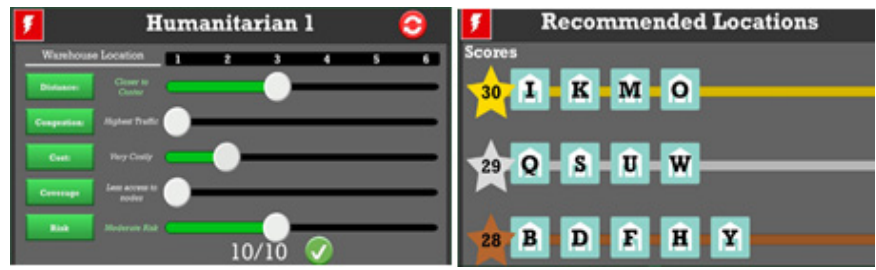

Figure 3: Screenshots of the Warehouse Location selection screen using the digital companion application

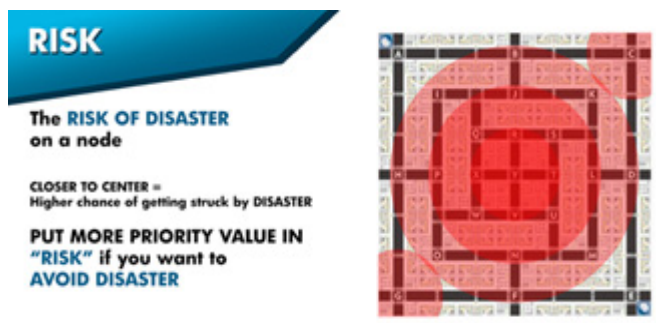

Figure 4: Sample screenshot of the MCDM criteria in the digital companion application

\subsection{Game Experience}

In November 2018, we conducted a workshop using the THINKLog game in Jakarta, Indonesia. This workshop was part of the ASEAN Coordinating Centre for Humanitarian Assistance on Disaster Management (AHA) Centre Executive (ACE)
Programme conducted by the ASEAN Coordinating Centre for Humanitarian Assistance (AHA Centre). The exercise involved 16 senior government officials operating in disaster preparedness and response from multiple ASEAN countries, whom had limited knowledge in humanitarian logistics.

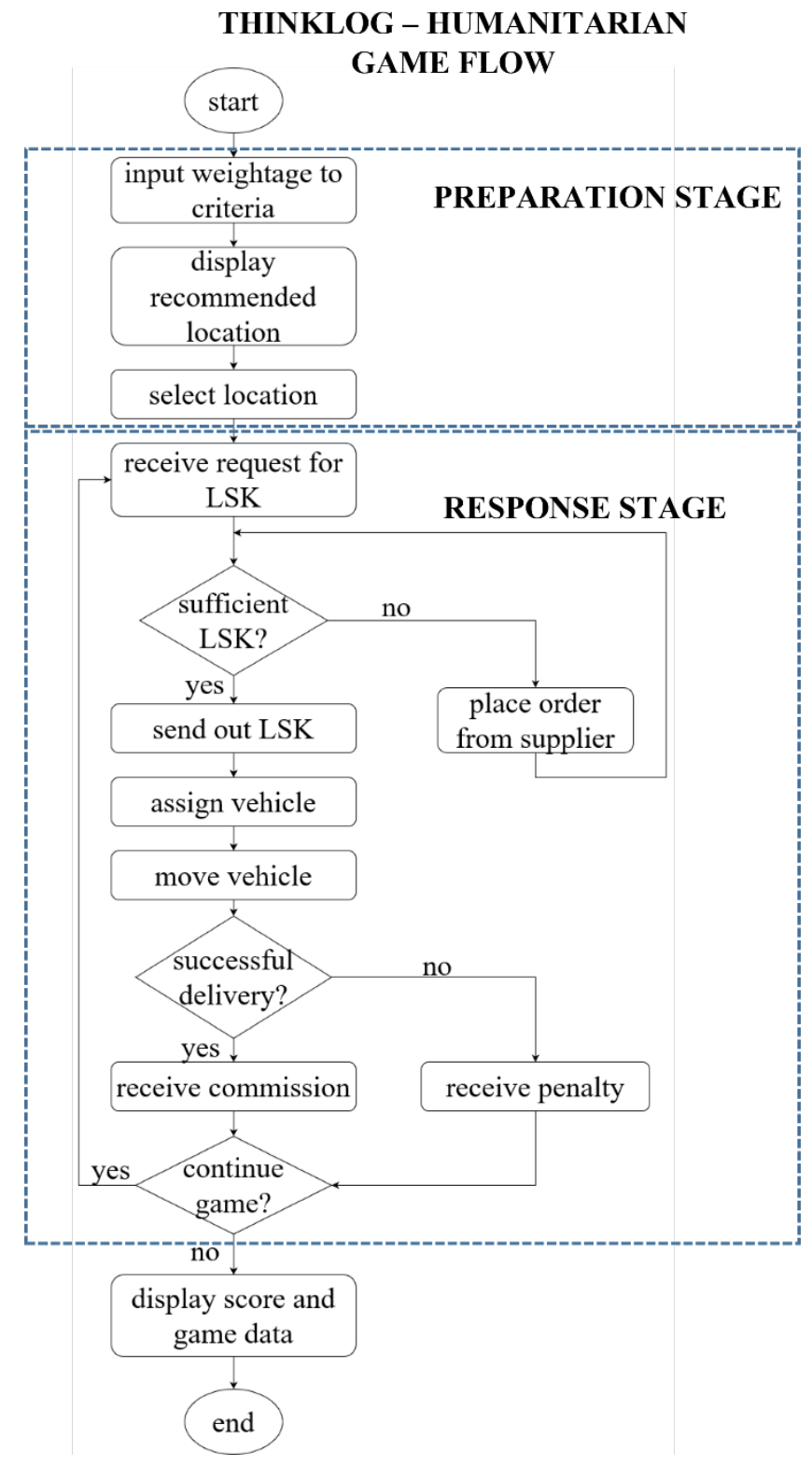

Figure 5: Basic game flow of THINKLog Humanitarian play

We conducted a brief presentation on humanitarian logistics and related supply chain concepts prior to the game play session. After the game play, participants were asked to fill up feedback forms. We then used those data to evaluate the impact of the game to increase the participants' understanding about humanitarian logistics and the overall game experience. We also used the workshop as a platform to gather inputs from the participants to be used in the simulation model.

The session allowed us to gather two separate sets of inputs. The first set is to evaluate participants' game experiences and it used a questionnaire of 14 questions. The sample of questions are shown in Table 2 below. 
Table 2: Sample of feedback questions

$\begin{array}{ll}\text { 0: Strongly disagree } \quad \text { 1: Disagree } \quad \text { 2: Neutral } 3: \text { Agree 4: } & \text { Strongly agree }\end{array}$

\begin{tabular}{|c|c|}
\hline Your Opinion & Rate (0-4) \\
\hline $\begin{array}{l}\text { 1. I feel that the whole session is } \\
\text { interesting }\end{array}$ & $0-1-2-3-4$ \\
\hline $\begin{array}{l}\text { 2. I would like to play this game } \\
\text { again in future }\end{array}$ & $0-1-2-3-4$ \\
\hline $\begin{array}{l}\text { 3. I encounter difficulties in } \\
\text { understanding the game rules }\end{array}$ & $0-1-2-3-4$ \\
\hline $\begin{array}{l}\text { 4. I know exactly what I need to do } \\
\text { in the game }\end{array}$ & $0-1-2-3-4$ \\
\hline $\begin{array}{l}\text { 5. I feel that every steps/decisions } \\
\text { made in this game has meaningful } \\
\text { meaning }\end{array}$ & $0-1-2-3-4$ \\
\hline 6. I feel very involved in this game & $0-1-2-3-4$ \\
\hline $\begin{array}{l}\text { 7. Interaction with other players } \\
\text { motivates me to understand this } \\
\text { game better }\end{array}$ & $0-1-2-3-4$ \\
\hline 8. Overall session is too long/boring & $0-1-2-3-4$ \\
\hline $\begin{array}{l}\text { 9. The game motivates me to ask } \\
\text { questions/discuss }\end{array}$ & $0-1-2-3-4$ \\
\hline $\begin{array}{l}\text { 10. I obtained interesting information } \\
\text { through this session }\end{array}$ & $0-1-2-3-4$ \\
\hline $\begin{array}{l}\text { 11. I am interested in the content } \\
\text { provided in this game }\end{array}$ & $0-1-2-3-4$ \\
\hline $\begin{array}{l}\text { 12. I did not learn anything from this } \\
\text { session }\end{array}$ & $0-1-2-3-4$ \\
\hline $\begin{array}{l}\text { 13. The Companion App helps me } \\
\text { understand the game }\end{array}$ & $0-1-2-3-4$ \\
\hline $\begin{array}{l}\text { 14. The Companion App helps me } \\
\text { learn from the game }\end{array}$ & $0-1-2-3-4$ \\
\hline
\end{tabular}

Participants were asked to provide answers using the 5-point Likert scale with 1 as strongly disagrees and 5 as strongly agree. There were sixteen valid responses received. The positive experience's average score is above 3 and the negative experience's is below 2, as shown in Figure 6. We may conclude that the participants had a good overall game experience.

The second feedback asked the participants to list down the key learning points that they have gathered from the session. We then compared the responses with the game's intended learning objectives. We received ten valid responses. We extracted the responses and identified the topics that they mentioned in their responses. The topics and the connection between the topics are shown in Figure 7.

From the analyzed feedback forms, we identified three main topics, namely: Plan, Warehouse and Location. Three out of six responses (3/6) that mentioned about Plan also mentioned about Warehouse and Location. It can be further breakdown to important considerations for planning the warehouse location, such as distance, congestion, cost, coverage and risk.

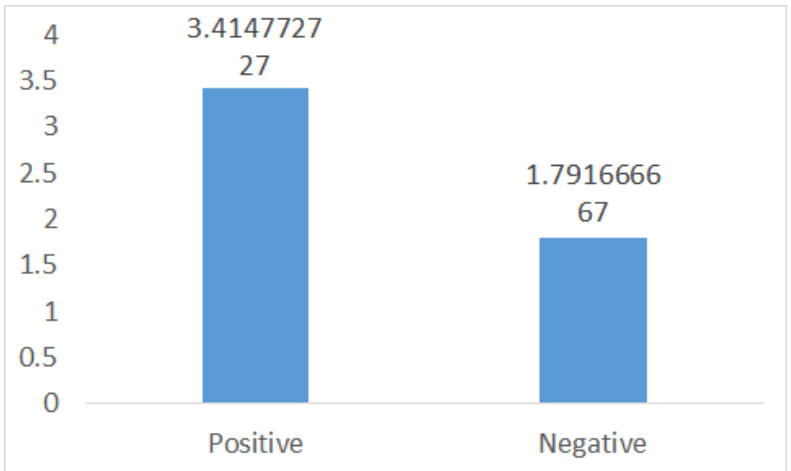

Figure 6: Overall experience

With the results, we are able to conclude that:

- The participants' learning outcome is aligned with the game's learning objectives.

- The game exposes the participants to the humanitarian logistics complexity.

- The feedback confirmed the need of embedding key elements such as distance (closeness to affected areas), congestion (the lower, the better), cost (the lower, the better), coverage (closer to highly populated disaster prone areas) and risk (facility to be located in a disaster free zone).

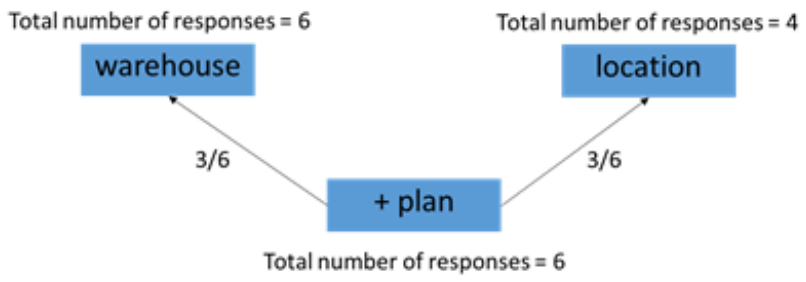

Figure 7: Learning Outcome

In addition, we also recorded the practitioners' inputs during and after the game session. Their inputs include the critical criteria to use for determining the location of a warehouse, and the importance of each criterion.

The feedback shows that the game enhances the players' awareness to the importance of decision making, especially in facility location. Players spent a substantial amount of time inputting the weightage for the criteria, deliberating which criteria should be of a higher importance. As the game provides 5 selected decision criteria for the MCDM, the players are more eager to 


\section{Z.B. Abdul-Rahim et al. / Advances in Science, Technology and Engineering Systems Journal Vol. 5, No. 3, $402-410$ (2020)}

experiment these using real-data simulation model that incorporates even more criteria for consideration, which will also involve the framework of selecting those criteria. Table 3 shows the criteria that was selected for the THINKLog game as compared to the criteria used for the model in Section 4.4. [41]

During the game play session, it was also noted that most, if not all, players placed higher weightage to Risk and Access to affected zones criteria. All players have the same number of vehicles ( 2 trucks) and warehouse capacity ( 30 LSK) in the game. As the game has only 1 disaster area (demand point), this may be sufficient. Whereas in real-life situation, there may be more than 1 demand point at any given point of time during a disaster.

Also, for this game play configuration, we intentionally excluded the transportation cost that may occur to deliver the LSK to the disaster area, for ease of play purpose. As such, the player may not be able to optimize its relief operation.

Table 3: The criteria used in THINKLog game

\begin{tabular}{|c|c|c|}
\hline Criteria & $\begin{array}{l}\text { Description used in THINKLog } \\
\text { game }\end{array}$ & $\begin{array}{l}\text { THINKLog } \\
\text { game }\end{array}$ \\
\hline Coverage & $\begin{array}{l}\text { Refers to the number of nodes } \\
\text { connected. }\end{array}$ & $\checkmark$ \\
\hline $\begin{array}{l}\text { Access to } \\
\text { affected zones }\end{array}$ & $\begin{array}{l}\text { Refers to the time taken from when } \\
\text { the order is placed till the order is } \\
\text { delivered. The closer one is to the } \\
\text { affected area, the shorter lead time it } \\
\text { will have, }\end{array}$ & $\checkmark$ \\
\hline Risk & $\begin{array}{l}\text { Refers to the chance of a disaster } \\
\text { striking the node. }\end{array}$ & $\checkmark$ \\
\hline $\begin{array}{l}\text { Access to } \\
\text { infrastructure }\end{array}$ & Not used in the game & $x$ \\
\hline $\begin{array}{l}\text { Access to } \\
\text { corridor }\end{array}$ & Not used in the game & $x$ \\
\hline Congestion & $\begin{array}{l}\text { Refers to the frequency of traffic } \\
\text { congestions happening around that } \\
\text { area }\end{array}$ & $\checkmark$ \\
\hline Cost & $\begin{array}{l}\text { Refers to the maintenance cost of a } \\
\text { warehouse in a node. The area around } \\
\text { the downtown costs higher than those } \\
\text { at the outskirt }\end{array}$ & $\checkmark$ \\
\hline $\begin{array}{l}\text { National } \\
\text { development } \\
\text { plan (NDP) }\end{array}$ & Not used in the game & $x$ \\
\hline
\end{tabular}

Section 4.4 describes the model we have developed to help locate the most appropriate alternative locations for the warehouse (facilities) to serve the different demand points, taking into consideration the transportation cost.

\subsection{Simulation Model for Humanitarian Logistics}

Based on the practitioners' input and the game session's outcomes of the game play, we developed a computer simulation model to delve the understanding on network design for stockpile prepositioning in the use case of Indonesia. The aim of this model was to determine, out of 9 alternative locations, which were the www.astesj.com most appropriate 6 sites to use for the positioning of emergency response facilities.

There were 186 demand points identified across the archipelago. Each demand points is served by a single facility. The model's overarching objective is to identify the possible locations for the facilities to serve these demand points, while keeping the transportation cost at the minimum. We used the actual distance and land fuel cost in this model to calculate the transportation cost between the facility and demand points. For those demand points without land connections (e.g. small islands), we set the fuel cost to extremely high values as to replicate intermodal transportation.

The results of the model are summarized in Figure 8 while the entire case study can be found in the paper by The Logistics Institute - Asia Pacific [42]. Figure 8(a) and 8(b) show possible network configurations identified by the computer model whereas figure 8 (c) shows the network structure prospected by discussions with practitioners.

By inputting these 3 alternative network configurations into the model, findings show that the network structure identified using network optimization has the potential to reduce the transportation cost by $15 \%$.
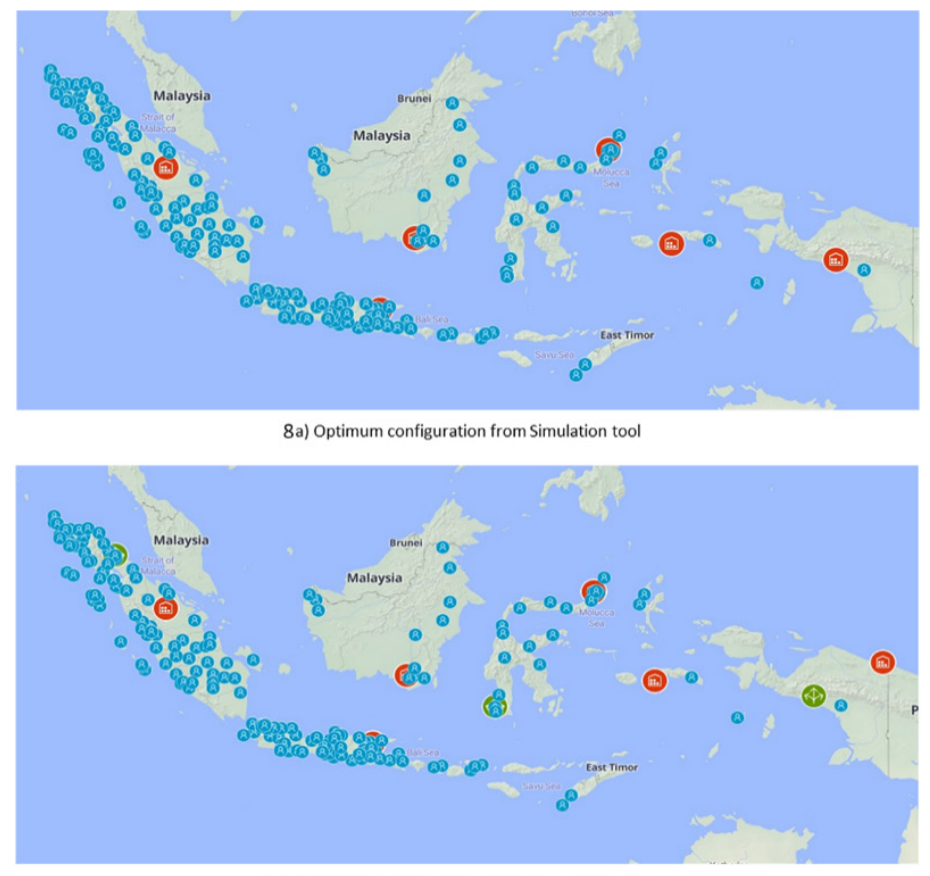

8b) Second best configuration from Simulation tool

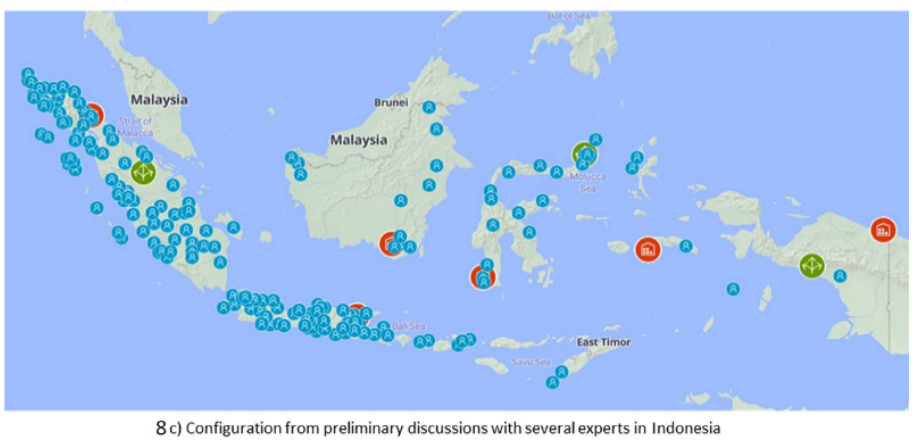

Figure 8: Disaster Relief Model 


\section{Z.B. Abdul-Rahim et al. / Advances in Science, Technology and Engineering Systems Journal Vol. 5, No. 3, 402-410 (2020)}

Subsequently, we stress-tested the network configuration upon two key logistics parameters namely fleet size and inventory. Figure 9 shows the results of the computer simulation model in regard to service level at when fleet size and inventory are set at different values.

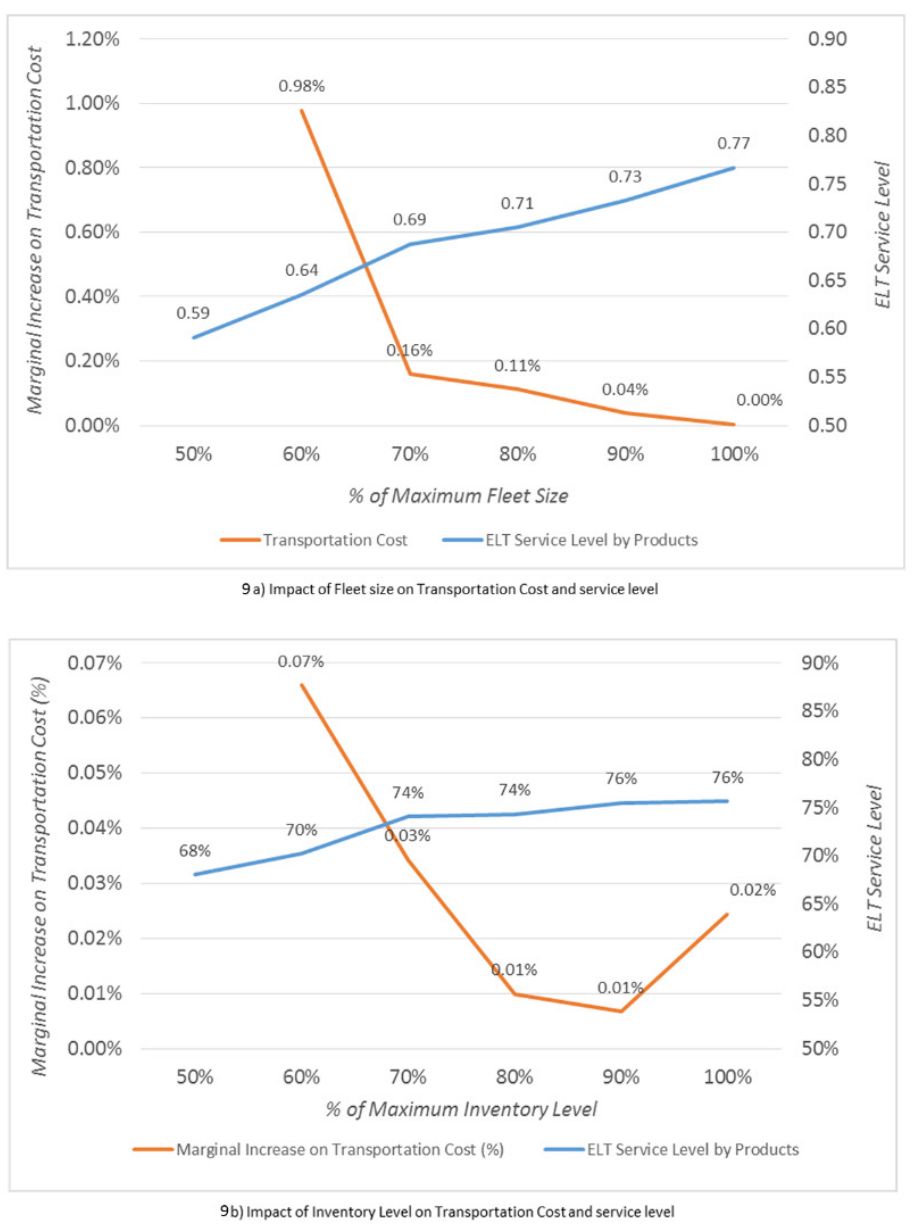

Figure 9: Simulation Result for Fine-tuning the Network Configuration on Two

\section{Conclusion}

Parameters

In this paper, the focus was on integrating serious games and computer modelling as a novel way to raise awareness on humanitarian logistics issues as well as to facilitate the acquisition of inputs from humanitarian practitioners. A real-case simulation model was developed with the aim of selecting the most suitable locations for establishing a network of facilities for prepositioning stocks of life-saving goods in Indonesia. We also had preliminary discussions with several experts on a prospected network configuration. When we compared these two configurations, the simulation model configurations allow for an estimated cost saving of $15 \%$.

A role-based board game, THINKLog, is proposed as an easy-to-use tool to raise awareness in humanitarian logistics for non-technical personnel. The game has two stages, the Preparation and Response stage. The feedbacks gathered from the game play session shows that the participants have a good overall game experience with a substantial positive influence on the players. This is supported by an evaluation of the learning objectives by the participants whom reported that they were able to grasp them during the game play.

This work has few limitations. First, the sample size of senior government officials operating in disaster preparedness and response from multiple ASEAN nations is fairly small. Playing the game with a larger group of practitioners would allow to gather deeper insights on the game play and inputs to the computer model. Secondly, on the simulation model, the dataset on small and medium scale disasters is confined to the biennium 2014-2015. An extension of this database with the inclusion of a greater number of disasters would provide a more accurate estimation of demand.

For future extension, we see an opportunity to add more immersive game features to the game, like augmented reality (AR). This may enhance the game's visualization and overall gameplay experience. Secondly, we would like to evaluate the THINKLOG game using a broader group of individuals with different age groups, educational and professional backgrounds, and level of understanding of supply chain and humanitarian logistics concepts. This would enable us to gather a more comprehensive view of game's ability to raise awareness.

\section{Conflict of Interest}

The authors declare no conflict of interest related to this paper.

\section{Acknowledgment}

The THINKLog board game was first developed as part of "Temasek Foundation International -National University of Singapore Urban Transportation Management Programme in Indonesia" programme. It is supported by Temasek Foundation International and Coordinating Ministry for Economic Affairs of Indonesia.

\section{References}

[1] R. D. de Souza, L. William, G. Timperio and Z. B. A. Rahim, "Simulation M And Simulation-Based Serious Gaming In Humanitarian Logistics," in Winter Simulation Conference, 2018.

[2] ReliefWeb, "The human cost of natural disasters 2015: a global perspective," $62015 . \quad$ [Online]. Available: https://reliefweb.int/report/world/human-cost-natural-disasters-2015global-perspective. [Accessed 512 2017].

[3] Swiss Re Institute, "Natural catastrophes and man-made disasters in 2017: a year of record-breaking losses," Swiss Re Institute, 2018.

[4] L. Van Wassenhove, "Humanitarian Aid Logistics: Supply Chain Management in High Gear," Journal of Operational Research Society, vol. 57, no. 5, pp. 475-489, 2006.

[5] A. S. Thomas and L. R. Kopczak, "Fritz Institute," 2005. [Online]. Available:

http://www.fritzinstitute.org/pdfs/whitepaper/fromlogisticsto.pdf. [Accessed 25 March 2016].

[6] B. Balcik and M. Beamon, "Facility Location in humanitarian relief," International Journal of Logistics: Research and Applications, vol. 11, no. 2, pp. 101-121, 2008.

[7] Y. Nahleh, A. Kumar and F. Daver, "Facility Location Problem in Emergency," International Journal of Mechanical, Aereospace, Mechatronic, and Manufacturing Engineering, vol. 7, no. 10, pp. 2113$2118,2013$.

[8] C. L'Hermitte, B. Brooks, M. Bowles and P. Tatham, "Investigating the strategic antecedents of agility in humanitarian logistics," Disasters, vol. 41, no. 4, p. 672-695, 2016. 


\section{Z.B. Abdul-Rahim et al. / Advances in Science, Technology and Engineering Systems Journal Vol. 5, No. 3, $402-410$ (2020)}

[9] G. Timperio, G. Panchal, A. Samvedi, M. Goh and R. De Souza, "Decision support framework for location selection and disaster relief," Journal of Humanitarian Logistics and Supply Chain Management, vol. 7, no. 3, pp. 222-245, 2017.

[10] C. Thierry, G. Bel and A. Thomas, "Supply Chain Management Simulation: An Overview," in Supply Chain Management Simulation, Wiley-ISTE; 1 edition , 2008, pp. 1-39.

[11] M. Besiou, O. Stapleton and L. N. Van Wassenhove, "System dynamics for humanitarian operations," Journal of Humanitarian Logistics and Supply Chain Management, vol. 1, no. 1, pp. 78-103, 2011.

[12] O. Costa, J. Santos, M. Martins and U. Yoshizaki, "A system dynamics analysis of humanitarian logistics coordination," Delft, 2015.

[13] E. Iakovou, D. Vlachos, C. Keramydas and D. Partsch, "Dual sourcing for mitigating humanitarian supply chain disruptions," Journal of Humanitarian Logistics and Supply Chain Management, vol. 4, no. 2, pp. 245-264, 2014.

[14] D. Noreña, R. Akhavan-Tabatabaei and L. Yamín, "Using discrete event simulation to evaluate the logistics of medical attention during the relief operations in an earthquake in Bogota," Phoenix, AZ, USA, 2011.

[15] V. Grimm and S. F. . Railsback, "Individual-based Modeling and Ecology," 17 May 2004. [Online]. Available: http://www2.humboldt.edu/ecomodel/documents/Grimm-Railsback05.pdf. [Accessed 20 August 2017].

[16] M. W. Horner and M. J. Widener, "The effects of transportation network failure on people's accessibility to hurricane disaster relief goods: a modeling approach and application to a Florida case study," Natural Hazards, vol. 59, no. 3, p. 1619-1634, 2011.

[17] U. Ritterfeld, M. Cody and P. Vorderer, "Serious games: Mechanisms and effects," Internationa Journal of Gaming and Computer-Mediated Simulations, vol. 1, no. 3, pp. 89-94, 2009.

[18] W. William, "Current trends in educational technology research: The study of learning environments," Educational Psychology Review, vol. 14, no. 3, p. 331-351, 2002.

[19] H.-T. Hou, "Integrating cluster and sequential analysis to explore learners' flow and behavioral patterns in a simulation game with situated-learning context for science courses: A video-based process exploration," Computers in Human Behavior, vol. 48, no. 1, pp. 424-435, 2015.

[20] M. Graafland, J. M. Schraagen and P. Schijven. M., "Systematic review of serious games for medical education and surgical skills training," British Journal of Surgery, vol. 99, no. 10, pp. 1322-1330, 2012.

[21] C. Lim and H. Jung, "A study on the military Serious Game," Advanced Science and Technology Letters, vol. 39, pp. 73-77, 2013.

[22] M. A. Garcia-Ruiz, J. Tashiro, B. Kapralos and M. V. Martin, "Crouching Tangents, Hidden Danger: Assessing Development of Dangerous Misconceptions within Serious Games for Healthcare Education," in Virtual Immersive and 3D Learning Spaces: Emerging Technologies and Trends, Kansas State University, USA, IGI Global, 2011 , p. 412.

[23] A. Gómez-Rodríguez, J. González-Moreno, D. Ramos-Valcárcel and L. Vázquez-López, "Modeling serious games using AOSE methodologies.," in 11th International Conference on Intelligent Systems Design and Applications, 2011.

[24] J. Hamari, D. Shernoff, E. Rowe, B. Coller, J. Asbell-Clarke and T. Edwards, "Challenging games help students learn: An empirical study on engagement, flow and immersion in game-based learning," Computers in Human Behavior, vol. 54, no. 1, pp. 170-179, 2016.

[25] M. Ma, A. Oikonomou and L. Jain, Innovations in Serious Games for Future Learning. In Serious Games and Edutainment Applications, London: Springer, 2011.

[26] PAXsims, "AFTERSHOCK," 4 2015. [Online]. Available: https://paxsims.wordpress.com/aftershock/.

[27] UN Office for Disaster Risk Reduction, "STOP DISASTERS!," 2019. [Online]. Available: https://www.stopdisastersgame.org/stop_disasters/.

[28] S. Conceição, S. Pedrosa, A. Neto, M. Vinagre and E. Wolff, "The facility location problem in the steel industry: a case study in Latin America," Production Planning \& Control, vol. 23, no. 1, pp. 26-46, 2010.

[29] H. Steenhuis and E. De Bruijn, "Production Planning \& Control," Assessing manufacturing location, vol. 15, no. 8, pp. 786-795, 2007.
[30] J. McCoy and M. Brandeau, "Efficient stockpiling and shipping policies for humanitarian relief: UNHCR's inventory challenge," Operations ResearchSpektrum, vol. 33, no. 3, pp. 673-698, 2011.

[31] S. Roh, S. Pettit, I. Harris and A. Beresford, "The pre-positioning of warehouses at regional and local levels for a humanitarian relief organisation," International Journal of Production Economics, vol. 170, no. Part B, pp. 616-628, 2015.

[32] System Dynamics Society, "Introduction to System Dynamics," 2010. [Online]. Available: http://lm.systemdynamics.org/what-is-s/. [Accessed 9 January 2018].

[33] S. Robinson, Simulation: The Practice of Model Development and Use, 1st ed., Chichester: John Wiley \& Sons Ltd, 2004.

[34] Statista, "Countries with the most earthquake fatalities 1900-2016," 2017. [Online]. Available: https://www.statista.com/statistics/269649/earthquake-deaths-by-country/. [Accessed 5 January 2018].

[35] AIR, "Five Countries Most Frequently Hit by Natural Disasters," 24 September 2015. [Online]. Available: http://www.airworldwide.com/Blog/Five-Countries-Most-Frequently-Hit-by-NaturalDisasters/. [Accessed 21 February 2018].

[36] Indonesia-investments, "Indonesia-investments," 6 une 2017. [Online]. Available: https://www.indonesia-investments.com/news/todaysheadlines/business-investment-climate-of-indonesia-improvingcompetitiveness/item7878. [Accessed 20 February 2018].

[37] Lindawati, E. Nugroho, R. Fredericco, Z. B. A. Rahim and R. de Souza, "ThinkLog: Interactive learning for supply chain management," in 2017 IEEE 6th International Conference on Teaching, Assessment, and Learning for Engineering (TALE), 2017.

[38] L. William, A. Rahim, R. de Souza, E. Nugroho and R. Fredericco, "Extendable Board Game to Facilitate Learning in Supply Chain Management," Science, Technology and Engineering Systems Journal, vol. 3, no. 4, pp. 99-111, 2018.

[39] M. Köksalan, J. Wallenius and S. Zionts, "An early history of multiple criteria decision making," Journal of Multi-Criteria Decision Analysis, vol. 1, no. 2, pp. 87-94, 2013.

[40] J. Brans, P. Vincke and B. Mareschal, "How to select and how to rank projects: The PROMETHEE method," European Journal of Operational Research, vol. 24, no. 2, pp. 228-238, 1986.

[41] The Logistics Institute - Asia Pacific, "How to identify the most appropriate locations for establishing an efficient network of emergency facilities? - A Discussion Paper," The Logistics Institute - Asia Pacific, Singapore, 2016.

[42] The Logistics Institute - Asia Pacific, "Integrated Decision Support Framework for Enhancing Disaster Preparedness: A Pilot Application in Indonesia," The Logistics Institute - Asia Pacific, Singapore, 2018. 